\title{
EVOLUSI TIPOLOGI PESISIR KAWASAN KARST DI PANTAI WATUKODOK KABUPATEN GUNUNGKIDUL
}

\author{
Henky Nugraha1, Ahmad Cahyadi², Efrinda Ari Ayuningtyas³, \\ Muhammad Abdul Azis Ramdani ${ }^{4}$ \\ 1,2,3,4 Karst Student Forum (KSF) Fakultas Geografi Universitas Gadjah Mada \\ 1,2,3 Magister Perencanaan Pengelolaan Pesisir dan Daerah Aliran Sungai \\ (MPPDAS) Fakultas Geografi Universitas Gadjah Mada Yogyakarta \\ 1,2,4Jurusan Geografi Lingkungan Fakultas Geografi Universitas Gadjah Mada \\ Email: ${ }^{1}$ nugrahahenky@gmail.com, 2ahmadcahyadi@geo.ugm.ac.id
}

\begin{abstract}
INTISARI
Kajian tentang evolusi tipologi akan sangat membantu dalam melakukan perencanaan pengelolaan di masa mendatang. Hal ini karena kajian tentang genesis suatu wilayah pesisir akan sangat membantu dalam melakukan analisis dinamika pesisir dan kerawanan terhadap bencana. Penelitian ini dilakukan di Pantai Watukodok, Kecamatan Tanjungsari, Kabupaten Gunungkidul yang merupakan objek wisata yang baru dikembangkan. Penelitian ini bertujuan untuk (1) mengetahui tipologi pesisir Pantai Watukodok, dan (2) melakukan rekonstruksi tipologi pesisir Watukodok Kabupaten Gunungkidul. Hasil analisis menunjukkan bahwa tipologi pesisir di Pantai Watukodok terdiri dari marine deposition coast dan wave erosion coast. Evolusi tipologi wilayah Pantai Watukodok dimulai dengan tipologi structurally shaped coast, kemudian berubah menjadi wave erosion coast, dan yang terakhir menjadi marine deposition coast.
\end{abstract}

\section{Kata Kunci : Evolusi, Karst, Tipologi Pesisir}

\section{PENDAHULUAN}

Geomorfologi merupakan ilmu yang mendeskripsikan bentuklahan dan proses yang terjadi di dalamnya dan menyelidiki hubungan secara spesifik antara bentuk dan proses dalam susunan keruangan (Zuidam dan Cancelado,1979). Objek kajian dalam studi geomorfologi adalah bentuklahan. Kajian mengenai bentuklahan tidak akan terlepas dari kajian genesis dan evolusi bentuklahan. Genesis dan evolusi bentuklahan dapat ditelusur dengan mengetahui proses geomorfologi yang bekerja pada bentuklahan. Proses geomorfologi yang bekerja secara terus menerus pada bentuklahan akan mengakibatkan perubahan pada bentuklahan (Sartohadi, 2007).

Proses geomorfologi yang bekerja pada bentuklahan tidak hanya akan terjadi pada saat ini atau waktu lampau saja, tetapi juga dapat terjadi pada 
masa yang akan datang, walaupun tidak dengan intensitas yang sama (Thornbury, 1954). Hal ini juga sesuai dengan prinsip geomorfologi "The present is the key to past" yang artinya bahwa kondisi sekarang merupakan kunci untuk melihat kondisi masa lalu. Proses geomorfik akan menginggalkan bekas pada bentuklahan yang dapat menjadi ciri dan sifat suatu bentuklahan. Bekas inilah yang dapat dijadikan sebagai salah satu indikator dalam mengetahui kondisi geomorfologi masa lalu. Susunan keruangan bentuklahan memberikan pengaruh kuat dalam mencirikan proses dan sifat dalam perubahan bentuklahan (Sartohadi, 2001). Pengetahuan mengenai geomorfologi baik bentuklahan maupun proses yang terjadi di dalamnya sangat penting dalam memahami karakteristik suatu wilayah.

Kawasan karst Gunungsewu merupakan salah satu kawasan karst yang ada di Indonesia. Kawasan ini memiliki karakteristik kondisi geomorfologi yang khas. Bemmelen (1949) memasukkan kawasan ini sebagai Zona Pegunungan Selatan bagian barat. Berdasarkan struktur geologinya, kawasan ini merupakan homoklin yang miring ke arah Selatan. Selain kondisi geologinya yang khas, kajian mengenai geomorfologi pesisir kawasan karst Gunungsewu sangat menarik untuk dikaji.

Marfai dkk (2012) menyatakan bahwa terdapat dua tipe tipologi pesisir pada kawasan karst Gunungsewu, yaitu pesisir primer dan sekunder. Tipologi pesisir primer yang terdapat di kawasan Karst Gunungsewu meliputi volcanic coast, land erosion coast, structurally shaped coast dan sub aerial deposition coast, sedangkan tipologi pesisir sekunder di kawasan karst Gunungsewu meliputi marine deposition coast, dan wave erosion coast. Tipologi pesisir ini terbentuk oleh genesis yang berbeda-beda.

Kajian mengenai geomorfologi pesisir di kawasan karst Gunungsewu khususnya evolusi tipoologi pesisir belum banyak dilakukan. Padahal, analisis terkait dengan evolusi tipologi pesisir akan sangat membantu dalam melakukan perencanaan pengelolaan di masa mendatang (Marfai dkk, 2012). Hal ini karena genesis suatu wilayah pesisir akan sangat berpengaruh terhadap dinamika pesisir dan kerawanan terhadap bencana (Cahyadi dkk, 2012; Marfai dan Cahyadi 2012; Mutaqin dkk, 2012).

Penelitian ini bertujuan untuk (1) mengetahui tipologi pesisir Pantai Watukodok, dan (2) melakukan rekonstruksi tipologi pesisir Watukodok Kabupaten Gunungkidul. Pantai Watukodok merupakan objek wisata yang dikembangkan di kawasan wisata Pantai Baron-Indrayanti, Kabupaten Gunungkidul. Adanya kajian ini diharapkan dapat menjadi salah satu referensi dalam pengelolaan lingkungan pesisir Pantai Watukodok pada khususnya, dan pesisir kawasan karst Gunungsewu pada umumnya dimasa mendatang. 

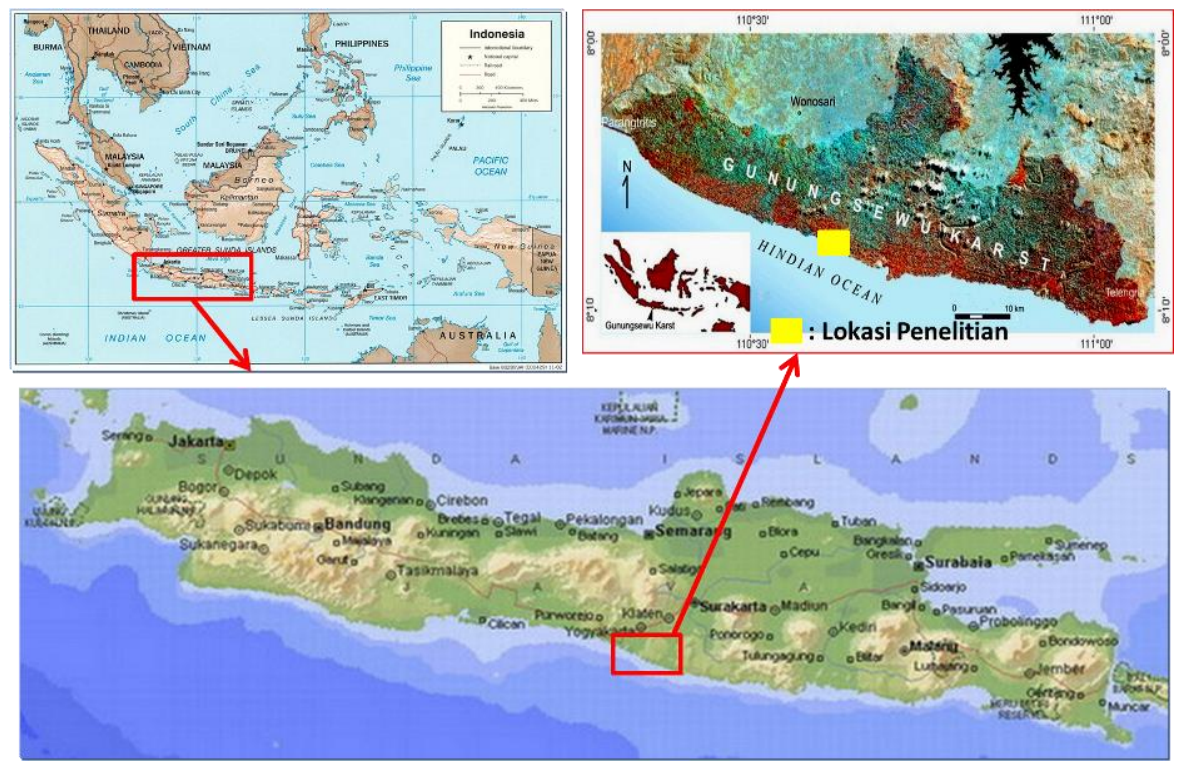

Gambar 1. Lokasi Penelitian

\section{METODE PENELITIAN}

Analisis evolusi tipologi pesisir Pantai Watukodok dilakukan dengan analisis bentuklahan. Bentuklahan merupakan wadah dan rekaman dari segala proses geomorfologi. Bentuk rekaman tersebut diantaranya berupa bentukanbentukan khas yang merupakan sisa dari proses yang yang telah berlangsung. Misalnya bentukkan gerongan pantai yang terdapat pada tebing yang merupakan bentukan dari aktivitas gelombang, serta gerongan pantai yang terletak pada tebing yang tinggi berarti menunjukkan adanya proses pengangkatan oleh proses struktural (Sunarto, 2003; Gunawan, 2005 dan Tjia dan Samodra, 2011).

Data yang digunakan dalam penelitian ini adalah bentuklahan dan data citra satelit Geoeye Tahun 2012. Data-data bentuklahan diperoleh melalui observasi lapangan dengan pendekatan geomorfologi serta pengukuran menggunakan sistem informasi geografis. Analisis data dilakukan secara deskriptif berdasarkan analisis geomorfologi. Analisis geomorfologi yang dimaksud dalam penelitian ini yaitu analisis keruangan bentuklahan yang meliputi morfologi, morfogenesa, morfokronologi dan morfoaransemen. 


\section{HASIL DAN PEMBAHASAN}

Tipologi pesisir yang terdapat di Pantai Watukodok Kabupaten Gunungkidul saat ini terdiri dari dua tipologi, yaitu tipologi marine deposition coast dan wave erosion coast (Gambar 2). Tipologi marine deposition coast membentuk gisik saku pada bagian teluk. Tipologi ini dicirikan dengan keberadaan material pasir yang merupakan hasil pengendapan oleh proses marin. Tipologi wave erosion coast terletak pada bagian tanjung dengan ciri kenampakkan berupa runtuhan batuan (stack) dan gerongan pantai.

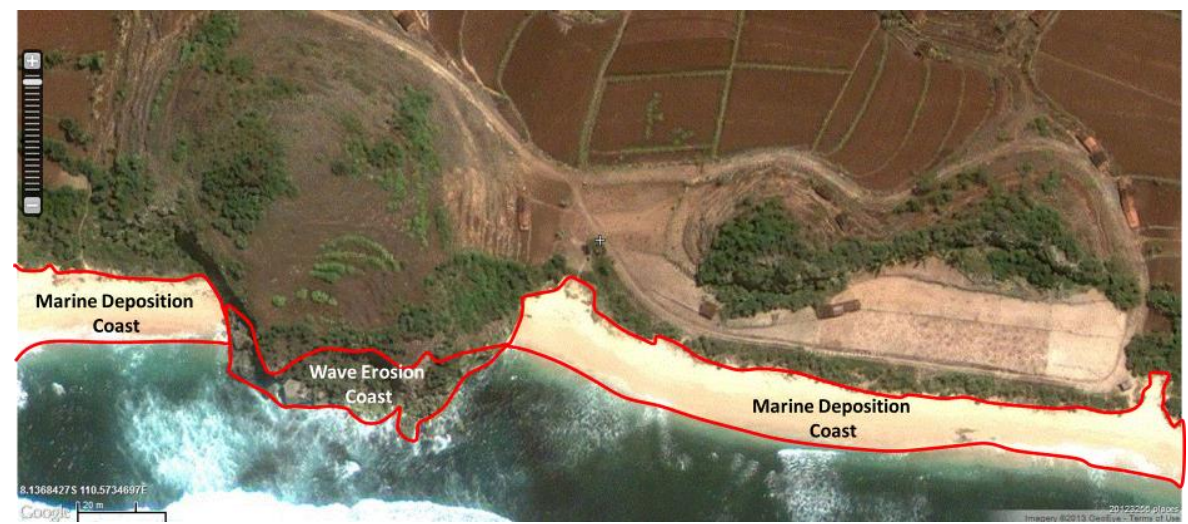

Gambar 2. Tipologi Pesisir Wilayah Penelitian Saat Ini

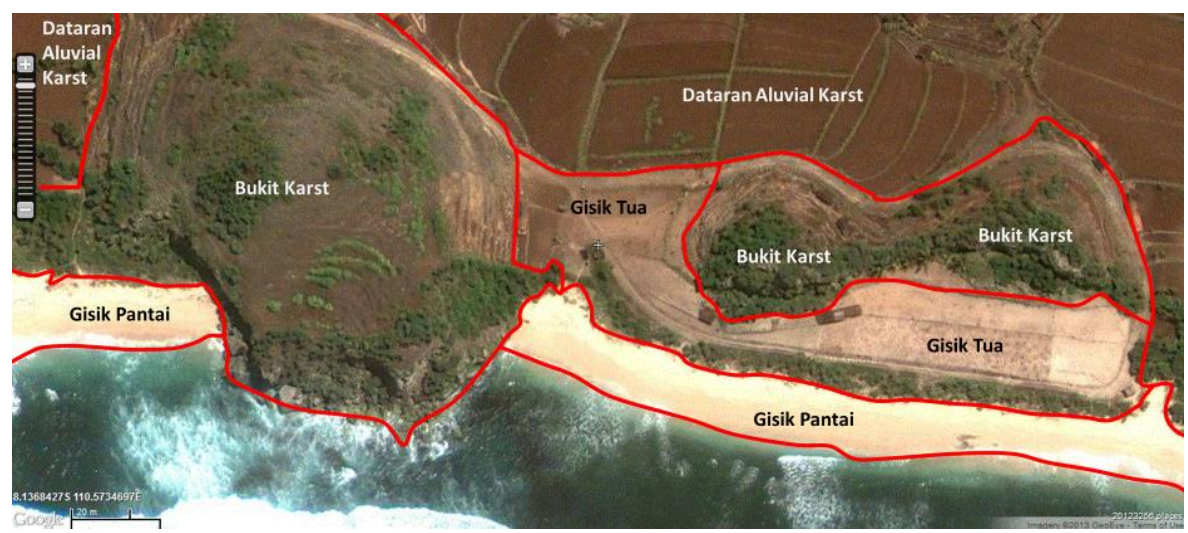

Gambar 3. Peta Geomorfologi Wilayah Penelitian

Tipologi pesisir yang terbentuk di Pantai Watukodok sangat terkait dengan kondisi geomorfologi. Gambar 3 menunjukkan bentuklahan yang terbentuk di Pantai Watukodok. Setidaknya terdapat empat bentuklahan, yaitu bukit karst, dataran alluvial karst, gisik pantai muda dan beting gisik (gisik 
tua). Dinamika pantai yang ditunjukkan pada wilayah ini berdasarkan bentuklahan yang terbentuk adalah berupa akresi pada wilayah gisik (tipologi marine deposition coast) dan abrasi di bagian bukit karst yang terletak di pantai (tipologi wave erosion coast).

Kenampakkan akresi pada marine deposition coast nampak dari bentuklahan beting gisik atau gisik tua yang merupakan perkembangan dari gisik pantai yang sudah tidak lagi terpengaruh pasang surut air laut, sedangkan fenomena abrasi nampak dari bentukkan gerongan pantai dan runtuhan batuan di bawah tebing (Gambar 4). Terjadinya akresi pada tipologi marine deposition coast juga nampak dari adanya runtuhan batuan yang terdapat di bawah tebing, yang menunjukkan adanya aktifitas gelombang pada masa lampau (Gambar 4). Selain itu, pada tebing bukit karst yang berbatasan dengan gisik tua juga diketemukan gerongan pantai, yang merupakan hasil aktivitas pada tipologi wave erosion coast (Gambar 5).

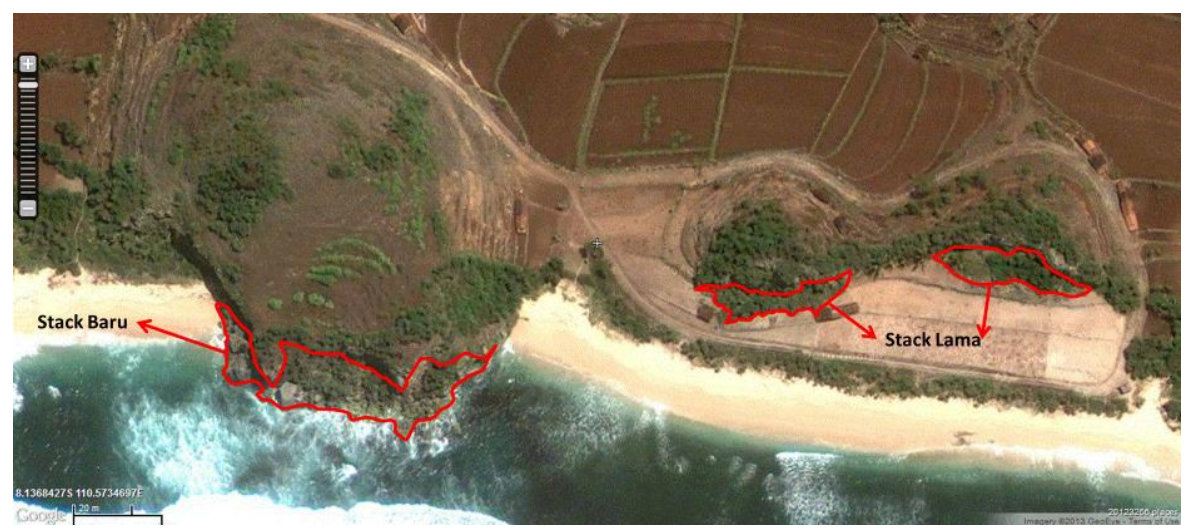

Gambar 4. Lokasi Runtuhan Batuan (Stack) Baru dan Lama di Wilayah Penelitian

Evolusi tipologi pesisir wilayah Pantai Watukodok tidak lepas dari sejarah geologi Plato Selatan Jawa. Pada Kala Pleistosen terjadi fluktuasi muka air laut yang mengakibatkan kenaikan dan penurunan muka air laut. Kloosterman (1989) dalam Sunarto (2004) menyatakan bahwa sekitar 18.000 tahun lalu suhu di dunia lebih rendah $3^{\circ}-6^{\circ}$ dari suhu saat ini. Hal ini menjadikan pembentukan lapisan es yang sangat tebal di berbagai belahan dunia. Fenomena ini biasa disebut sebagai Zaman Es yang terjadi pada Kala Pleistosen. Pada zaman ini air di lautan berubah menjadi es sehingga daratan menjadi lebih luas dari kondisi sekarang.

Peristiwa patahan dan penenggelaman Plato Selatan Jawa mengakibatkan daerah penelitian tergenang oleh air laut. Pada periode post glasial terjadi 
penurunan muka air laut sehingga garis pantai mundur hingga seperti saat ini (Sukandarrumidi, 2005). Menurut Bemmelen 1949, peristiwa penenggelaman Plato Selatan Jawa terjadi pada Kala Pliosen Awal (sekitar 4 juta tahun yang lalu). Penenggelaman ini disebabkan oleh patahan. Evolusi Jawa bagian tengah bergerak dari arah utara ke selatan yang menimbulkan tiga geoantiklin. Geoantiklin pertama yang terjadi pada Kala Miosen Tengah (sekitar lima belas juta tahun lalu) mengakibatkan pengangkatan pegunungan selatan yaitu Kawasan Karst Gunungsewu. Bagian yang terangkat ini kemudian mengalami patahan dan pada bagian selatan tenggelam membentuk garis cenderung lurus dan meninggalkan kenampakan tebing yang curam. Proses ini kemudian membentuk tipologi structurally shaped coast.

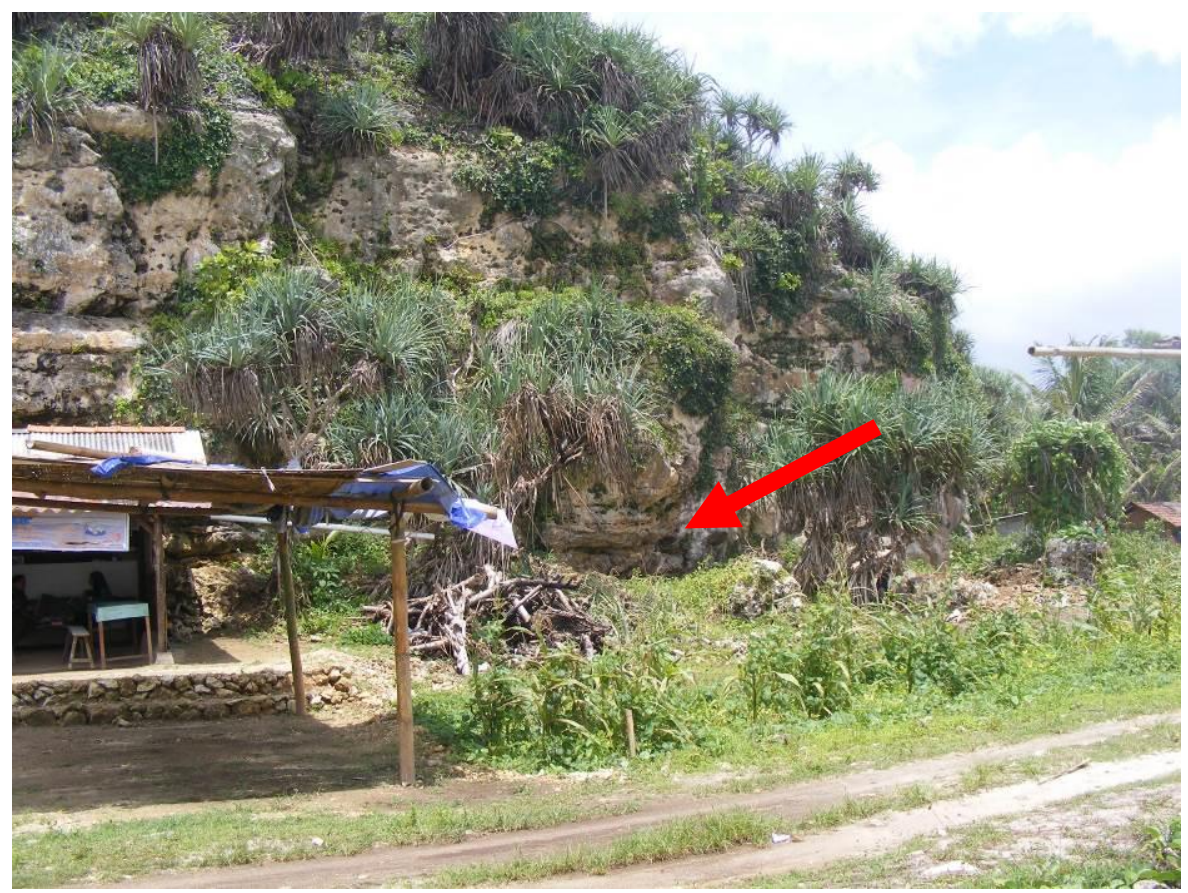

Gambar 5. Gerongan Pantai (Ditunjukkan Anak Panah) pada Tebing Bukit Karst yang Terdapat di Utara Beting Gisik (Gisik Tua)

Gambar 6 menunjukkan evolusi tipologi pesisir yang terjadi di Pantai Watukodok. Tipologi pertama adalah terbentuknya tipologi structurally shaped coast, yang ditandai dengan adanya tebing terjal dengan kemiringan ke arah Selatan. Tipe kedua yang muncul adalah wave erosion coast yang ditandai dengan adanya aktivitas gelombang yang menyebabkan terbentuknya 
gerongan pantai dan runtuhan batuan di bawah tebing. Aktivitas gelombang juga telah menyebabkan terjadinya tanjung dan teluk. Wilayah teluk kemudian didominasi dengan proses pengendapan sedimen oleh proses marin membentuk gisik saku yang merupakan tipologi pesisir marine deposition coast.

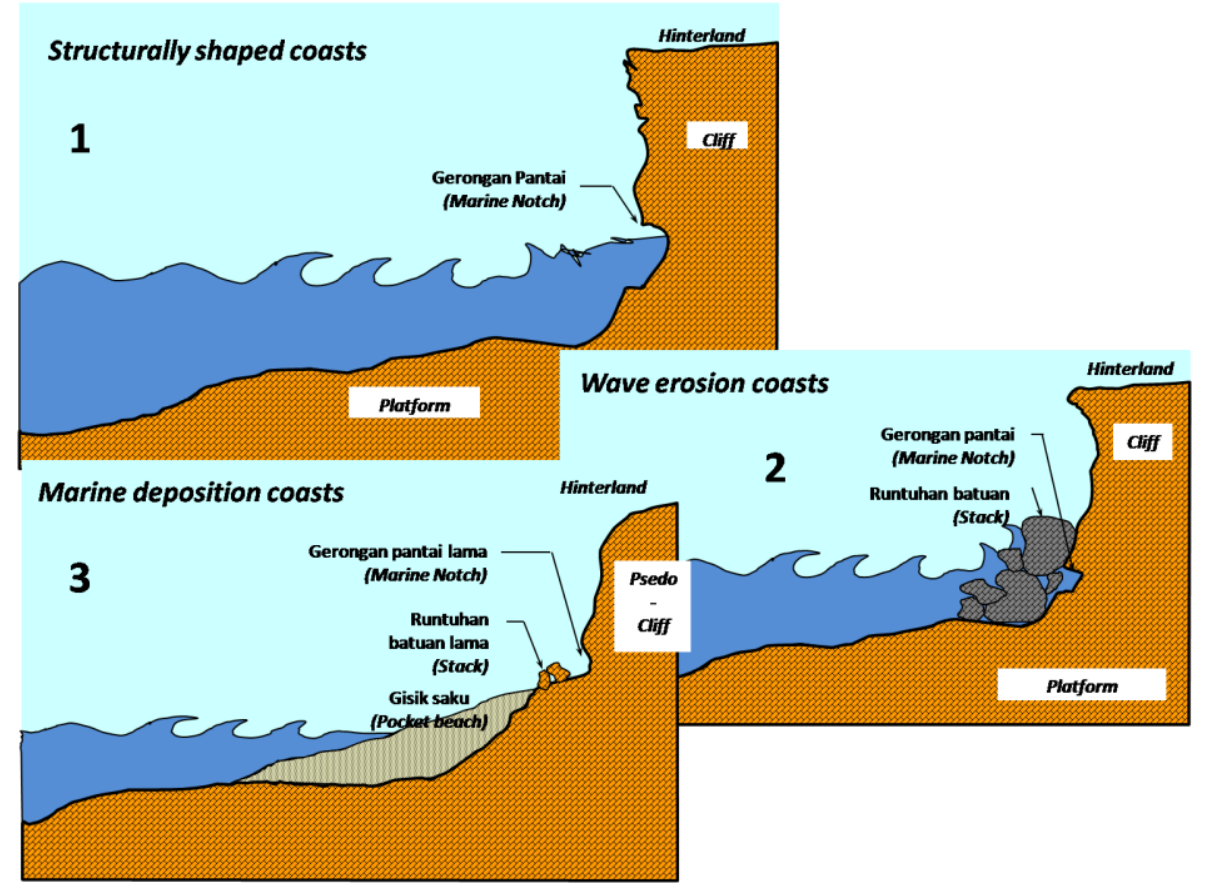

Gambar 6. Evolusi Tipologi Pesisir di Pantai Watukodok

\section{KESIMPULAN}

Berdasarkan hasil penelitian yang dilakukan, maka disimpulkan beberapa hal berikut:

1. Tipologi pesisir di Pantai Watukodok terdiri dari marine deposition coast dan wave erosion coast.

2. Evolusi tipologi wilayah Pantai Watukodok dimulai dengan tipologi structurally shaped coast, kemudian berubah menjadi wave erosion coast, dan yang terakhir menjadi marine deposition coast. 


\section{DAFTAR PUSTAKA}

Bemmelen, R.W. van. 1949. The Geology of Indonesia, Vol. IA. The Hague: Martinus Nijhoff.

Cahyadi, A.; Afianita, I.; Gamayanti, P. dan Fauziyah, S. 2012. Evaluasi Tata Ruang Pesisir Sadeng Gunungkidul: Perspektif Pengurangan Risiko Bencana. Makalah dalam Seminar Nasional Sustainable Culture, Architecture and Nature ke-3 Tahun 2012. 15 Mei 2012, Program Studi Arsitektur Fakultas Teknik Universitas Atma Jaya Yogyakarta.

Gunawan, T.; Santosa, L.W.; Muta'ali, L.; dan Santosa, S.H.M.B. 2005. Pedoman

Survei Cepat Terintegrasi Wilayah Kepesisiran. Yogyakarta: Badan Penerbit dan Percetakan Fakultas Geografi (BPFG).

Marfai, M.A. dan Cahyadi, A. 2012. Penentuan Tipologi Pesisir Rawan Tsunami di Provinsi D.I. Yogyakarta Berdasarkan Analisis Regional dan Local Site Effect. Jurnal Spatial, Vol. 10(2). Hal: 1-6.

Marfai, M.A.; Cahyadi, A; dan Anggraini, D.F.. 2012. Tipologi, Dinamika dan Potensi Bencana di Pesisir Kawasan Karst Kabupaten Gunungkidul. Laporan Penelitian. Magister Perencanaan Pengelolaan Pesisir dan Daerah Aliran Sungai, Fakultas Geografi, Universitas Gadjah Mada, Yogyakarta.

Mutaqin, B.W.; Cahyadi, A. dan Dipayana, G.A. 2012. Indeks Kerentanan Kepesisiran Terhadap Kenaikan Muka Air laut pada Beberapa Tipologi Kepesisiran di Propinsi Daerah Istimewa Yogyakarta, 21 Januari 2012. Makalah dalam Seminar Nasional Penginderaan Jauh dan Sistem Informasi Geografis 2012, Fakultas Geografi Universitas Muhammadiyah Surakarta.

Sartohadi, J. 2001. Geomorphological Analysis for Soil Mapping using Remote Sensing and Geographic Information Systems: A Case Study in Western Gunungkidul, Yogyakarta- Indonesia. Disertasi. Leopold Franzens Univerisyt of Innsbruck Austria.

Sartohadi, J. 2007. Terapan Geomorfologi dalam Pengelolaan Sumberdaya Air. Alami Vol. 12 (1) Tahun 2007.

Sukandarrumidi. 2005. Geologi Sejarah. Yogyakarta: Gadajah Mada University Press.

Sunarto. 2003. Geomorfologi Pantai: Dinamika Pantai. Makalah dalam Kegiatan Susur Pantai Karst Gunungkidul pada Raimuna 2003. Yogyakarta: Laboratorium Geomorfologi Terapan Fakultas Geografi Universitas Gadjah Mada.

Sunarto. 2004. Perubahan Fenomena Geomorfik Daerah Kepesisiran di Sekeliling Gunungapi Muria Jawa Tengah (Kajian Paleogeomorfologi). Disertasi. Universitas Gadjah Mada 
Thornbury, 1954. Principles of Geomorphology. John Wiley and Sons. London - New York

Tjia, H.D. dan Samodra, H. 2011. Active Crustal Deformation at The Coast of Gunungsewu, Jawa. Makalah dalam Asian Trans-Disciplinary Karst Conference, 7-10 Januari 2011. Fakultas Geografi Universitas Gadjah Mada, Yogyakarta.

Zuidam, R.A. van and Zuidam, F.I. van Cancelado, (1979). Aerial PhotoInterpretation in Terrain Analysis and Geomorphologic Mapping. ITC. Smits Publishers. The Hague

Makalah ini merupakan salah satu chapter dalam buku berjudul "Ekologi Lingkungan Kawasan Karst Indonesia: Menjaga Asa Kelestarian Kawasan Karst Indonesia", dengan Editor Sudarmadji, Eko Haryono, Tjahyo Nugroho Adji, M. Widyastuti, Rika Harini, Emilya Nurjani, Ahmad Cahyadi, Henky Nugraha. Buku ini diterbitkan di Yogyakarta Tahun 2013 oleh Penerbit Deepublish. Makalah ini dimuat di halaman 66-72. 